\title{
Research and Practice of One Test Question of Each Lesson
}

\author{
Jun Dong \\ Shan Dong Zibo Teaching and Research Office, Zibo, China \\ Email address: \\ 18753369018@163.com
}

\section{To cite this article:}

Jun Dong. Research and Practice of One Test Question of Each Lesson. Science Journal of Education. Vol. 7, No. 2, 2019 , pp. 58-64. doi: $10.11648 /$ j.sjedu. 20190702.12

Received: May 20, 2019; Accepted: June 29, 2019; Published: July 11, 2019

\begin{abstract}
Positioning as the beginning place of new lessons, the One Assignment per Lesson is not only a teaching link, but also an assignment or a group of assignments. It has two basic functions: The first function is to fully expose and solve problems. Problems found on the last course can be shown by the form of exercises (exercise set). Students exposed problems, and then these problems can be analyzed through the communication between students and teachers. The sticking problems made from all aspects of analysis will be solved completely and implemented into the following teaching. The second is to guide the teaching of new lessons with discipline thoughts and scientific principles. Find out the principles and rules from the knowledge of new lessons, and then design problems (problem set) or exercises (exercise set) by the principles and same knowledge that students have mastered. In doing that, it will inspire student to open mind, reason evidences, extract principles, form opinions, compose model, form model awareness, design experiment, practice innovation, study scientifically and form quality. Students can make a self-regulated learning, cooperation and communication, and pursuit and respect science on the platform of One Assignment per Lesson, and they will further form true value concepts, essential quality and key ability, achieving the education goal of teaching knowledge and cultivating people.
\end{abstract}

Keywords: One Assignment Per Lesson, Scientific Principle, Solve the Problem, Lead the Teaching, Teach Knowledge and Cultivate People

\section{Introduction}

By attending school lessons, the author has learnt that many teachers have their own views and approaches on the introduction of new lessons. The phenomenon of "one assignment a day" has developed in some secondary schools, the purpose is to emphasize students' participation and spirit, or to provide a platform for students to participate and enhance their confidence [1]; or reflect students' mutual evaluation and self-evaluation, to cultivate students' correct outlook on world, life and values [2]. High schools are more rational. In schools with relatively weak enrolment, most teachers introduce the knowledge of the new lesson by combining society and life, and elaborate its significance and stimulate students' interest; In schools with fairly good enrolment, the chemical problem-inquiry-construct (PIC) teaching model is used straight to the point, and the final assignment includes a comprehensive one assignment per leasson [3]. Generally, teachers comment on the last assignment when assigning homework. These practices are able to combine the actual situation of the students in the school and have many merits. However, the teaching design of a particularly independent and complete lesson starts from scratch and is brand-new. It separates a principled and systematic science into countless independent units. Science is knowledgeable, principled and structured, and learning science requires memorizing knowledge, more importantly, to understand knowledge from the basic principles with scientificideological method. In teaching, we should not only focus on how to teach, but also how to learn and how well do you learn is more noteworthy. What to learn? How to learn? How well do you learn? These are the objectives of teaching design and concrete reflection of the education thought of "based on development of students". On this account, through long-term research and practice in teaching design, the author has proposed a new concept ofone assignment per Lesson, detailed as below for comments and suggestions, such as the following: Why to Perform One Assignment per Lesson? 


\subsection{Guiding Subject Teaching with Subject Idea and Scientific Principle [4]}

Chemistry is a science to study matter and its changes and it involves many substances, properties and changes. After hundreds of years of research, experimentation and summary by scientists, it has formed a unique scientific concept, disciplinary ideological method and perfect theoretical system. It plays an exceptional role in understanding the knowledge system and structure of chemistry, and guiding scientific and effective learning of chemistry. Teachers should design teaching, and "focus students" personalized and diversified demands of learning and development, promote the mode transformation of talent cultivation, and develop students' core competence [5]. Therefore, when learning specific chemical knowledge, it is necessarily to analyze and recognize new substances and their changing laws regularly with discipline thought and basic principle, timely incorporate concrete new materials and knowledge into the structural system containing many laws of matter and nature. In this way, student's learning will be detached from the material theory of matter, from low-level, isolated, passive acceptance learning to the active, connected and principled learning with scientific perspective and principle. Consequently, under the guidance of scientific concept and disciplinary idea, scientific teaching means that teachers teach with scientific principles; and scientific learning means that students learn subject knowledge with active application of scientific principles and timely incorporated into the disciplinary knowledge system; only this teaching is serving the development of students' competence the goal of teaching knowledge and cultivating people.

\subsection{Finding and Solving Problems Is the Basic Work of Teaching}

Learning chemistry not only requires full understanding of the basic principles, and basic knowledge also needs to be consolidated. Without basic knowledge, guiding teaching with the discipline concept and learning chemistry with basic principles will become the water without a source and merely empty talk.

Correct understanding and memory of knowledge helps students to understand the principles of science and discover the laws of science; single-faceted or incorrect understanding and memory of knowledge will provide students an isolated and distorted impression to misconception, and influencing the future study. Therefore, find and solve problems in time is the basic work of teaching and an important step to improve teaching quality.

In general, students' problems in learning are found in the communication between the teacher and the students and school assignment. There are important issues, such as how to centralize feedback on the problems found. How to solve the problems thoroughly before the new lesson. How to make students expose the crux of the problem by themselves and teachers can directly solve the problem fundamentally, are affecting the quality of teaching and are the principal tasks in teaching research. Therefore, solving these problems should not be the random work of individual teachers; it is necessary to arrange the teaching link in a unified way to form a fixed link and problem-solving model. Thus, the teachers are able to solve the problem calmly and profoundly with fixed time and scientific and effective methods.

\section{Specific Implementation Method of One Assignment Per Lesson}

\subsection{Solving Problems and Extracting Ideas and Principles Should Be Completed Before the Teaching of New Knowledge}

Where and how do you get the scientific principles needed to learn new knowledge? This is a major issue that needs to be studied. It involves aspects in learning method, opportunity, structure, efficiency and significance. Based on study results and summary of the teachers' practice summary over the years, it can be concluded that students' basic knowledge is the best source of basic principles; students self-summarize the basic principles from the memory, practice and reinforcement of basic knowledge is the best form of acquiring basic principles; students recall the learned relevant knowledge before they start to learn new knowledge, and gain new insights through restudying old material to timely guide the learning of new knowledge is the optimal time for the generation and application of basic principles; under the unification of basic principles, timely incorporating new knowledge into learned knowledge structure to enrich or update the knowledge system, and turn the new knowledge into the basic material to feed back on the understanding of the basic principles and knowledge structure system, is the best structured learning; such method of extracting principle from knowledge and immediately apply it to guide the learning of new knowledge is the most efficient way of learning; this kind of purposeful, directional, problematic teaching design, starting with the study of specific cases, extracts essential principles which are beyond specific cases but with wide application value, and applied to guide new concrete cases is the most significant teaching design with best results and highest grade.

Correct knowledge can accumulate connotation and broaden our horizons and create association and enlighten minds. Therefore, students' problem is the priority of teaching. Hence, prior to the new lesson, the problem must be solved thoroughly from the basis of students' knowledge, depths of thinking and heart of the problem.

\subsection{One Assignment Per Lesson Has Multiple Functions and Has a Leading Role in Teaching}

After years of research, study and practice, an effective teaching link that is confirmed that can achieve the above goals and is recognized by the majority of teachers - one assignment per lesson.

One assignment per lesson is a teaching link and also a practical exercise.

This link is at the beginning of each lesson. The time is generally 
about 5 minutes, and content is 1 - 2 exercises or exercise set, it can be a summary for students' questions in the previous lesson, or discipline thought method that students should possess in the learning of this lesson, which can be distributed in different exercises. The form of learning is to combine students' analysis and elaboration with communication and comments from teachers [6], consolidation of basic knowledge with the refinement of basic principles, and intensification of specific knowledge and formation of basic concept.

One assignment per lesson is exercises compiled by teachers. It reflects teachers' understanding and response on students' learning situation, and is integration, embodiment and instance of students' problems. Teachers can choose students with problems in their homework to demonstrate, expose problems and interpreting their own thoughts and understanding on board, so as to reflect the root cause of the problem; by constantly asking questions, teachers analyze the root causes of students' mistakes in depth, to realize false case analysis and teaching, and solve the problem thoroughly and fundamentally, to enable students with thorough understanding, and educate all students at the same time.

One assignment per lesson is exercises compiled by teachers. It reflects teachers' educational ideas, and filled with teachers' own understanding, grasp and application of chemistry. By self-solving problems, students are able to extract the basic principles from the learned basic knowledge and apply to the learning of new knowledge. It is not only a further understanding and deepening of the learned basic knowledge and principles, but also to realize the application of basic principles and deepen understanding in application by drawing inferences. Therefore, one assignment per lesson is the link and bridge connecting old and new knowledge, a platform for extracting basic principles, and the combination of science teaching and learning, the first step in scientific learning, and it leads the teaching [7].

\section{Basic Types of One Assignment Per Lesson}

As explained previously, one assignment per lesson has two objectives, extracting ideological method and basic principles, and exposure and problem solving. Accordingly, it is classified and reported as follows:

\subsection{Principle Extraction Application Type}

For example, in the elective course 4, when learning Hess's Law, the understanding and application of its meaning is a difficult point. To compile one assignment per lesson based on the knowledge of the relationship between bond energy and reaction heat of chemical bonds available to students can realize the smooth connection and application of the basic principles. It reduces the difficulty of learning, as well as achieving the through understanding and expansion of basic principles. Examples are as follows:

Example 1. Black phosphorus with stable structure can react with $\mathrm{Cl}_{2}(\mathrm{~g})$ to produce $\mathrm{PCl}_{5}(\mathrm{~g})$. However, the industrial preparation of $\mathrm{PCl}_{5}$ is generally divided into two steps: first, $\mathrm{P}(\mathrm{s})$ is reacted with $\mathrm{Cl}_{2}(\mathrm{~g})$ to produce the intermediate $\mathrm{PCl}_{3}(\mathrm{~g})$, and then it is cooled, and then reacts with $\mathrm{Cl}_{2}(\mathrm{~g})$ to form $\mathrm{PCl}_{5}(\mathrm{~g})$. The transformation relationship between the three can be shown in Figure 1. The relationship between reaction process and energy is shown in Figure $2(\Delta \mathrm{H}$ in the figure represents the data for the production of 1 mol product) [8].

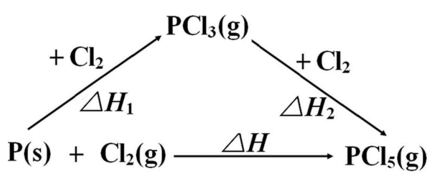

Figure 1. Transformation relationship between $\mathrm{P}(\mathrm{s}), \mathrm{PCl}_{3}(\mathrm{~g}), \mathrm{PCl}_{5}(\mathrm{~g})$.

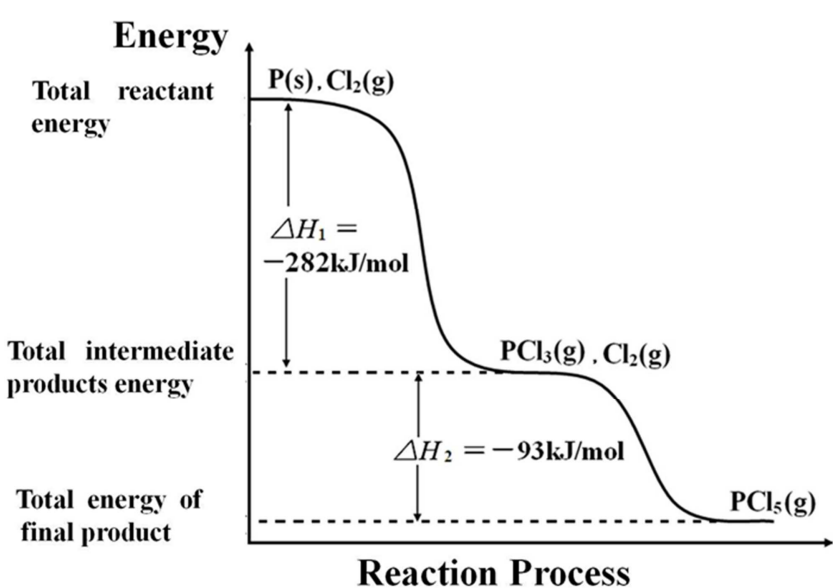

Figure 2. $\mathrm{P}(\mathrm{s})$ and $\mathrm{Cl}_{2}(\mathrm{~g})$ reaction process with the energy of the relationship between the map.

Please answer the following questions:

Question 1: Explain why is the reaction of $\mathrm{PCl}_{3}$ to $\mathrm{PCl}_{5}$ is exothermic from the reaction principle?

Question 2: Given that the bond energy of $\mathrm{Cl}-\mathrm{Cl}$ is 243 $\mathrm{kJ} / \mathrm{mol}$. Please calculate the average bond energy of the newly formed $\mathrm{P}-\mathrm{Cl}$ bond in reaction 2 .

Question 3: What is the relationship between the total reaction equation and the equation for reaction 1 and reaction 2 ?

Question 4: Given that formation enthalpy $\Delta \mathrm{H}$ by $\mathrm{PCl}_{5}=375$ $\mathrm{kJ} / \mathrm{mol}$. Please determine the relationship between $\Delta \mathrm{H}$ and $\Delta \mathrm{H}_{1}$ and $\Delta \mathrm{H}_{2}$ in the total reaction. Please use the words and computational expressions.

Question 5: How do you understand the relationship between the above reaction heats from the perspective of chemical bonds?

Question 6: Can you calculate $\Delta \mathrm{H}$ for another step reaction based on $\Delta \mathrm{H}$ for the total reaction and $\Delta \mathrm{H}$ for one step reaction?If yes, please list the formulas.

Finally, the teacher combines the result with Hess's law and concludes: based on the above formulas and calculation results, it can be seen that, under certain conditions, the heat released by the reaction is only related to the bond energies of reactants and products. In other words, the enthalpy change of the reaction is only related to the total state of the reaction, not the reaction process. Therefore, students can form a conceptual model of the relationship between energy and reaction process in their minds 
[9]. It has realized the knowledge development and growth of the relationship between chemical reaction and $\Delta \mathrm{H}$, and laid a foundation and built a bridge for the subsequent learning of Hess's law. The learning style has changed from knowledge acceptance type to profound understanding, summarize and reasoning, principle application, thought training and ability training, from passive to active, so the quality of learning has undergone a qualitative change.

It is clear that the principle extraction application type one assignment per lesson mainly focuses on summarizing and reasoning from a collection of facts and extracting and applying basic principles.

The first demonstration of one assignment per lesson teaching link is in the open teaching seminar of high school chemistry teaching in Zibo. The teachers were amazed that Chemistry could be taught in this way. There is no fixed teaching approach, and no poorly taught students, but only teachers who cannot teach.

The value of principle is its essence, regularity, application and guidance. Therefore, when learning knowledge, one must fully respect and highlight its basic principles, taking the principle to be the main line, combining the reviewing of learned knowledge with the study of new knowledge. The whole learning process becomes the process of summarizing, understanding and applying of basic principles; in terms of learning process, there is no wide gap between review and new teaching; in terms of knowledge, there is no step between known and unknown; and in terms of learning connotation, there is no difference between knowledge and thinking. On the basis of learned knowledge, students can combines knowledge with thinking autonomously, so the learning process is natural and smooth. In independent learning and cooperative communication, all students are able to complete the principle extracting, thinking development and new knowledge learning.

Taking another example, when learning metal sodium in Chemistry 1, the method of recalling with the reference to the textbook can be used [10], from the perspective of structure determines the nature and ideological method of classification, in accordance with the relationship between the commonality of metals, atomic structure and the properties of elements learnt in junior high school. This is the method most schools teach. But analyzed from the point of view of principle, students can also apply and learn with the redox reaction theory just learned. This is not choosing a different path, but following the principle of redox reaction. One assignment per lesson in learning sodium metal takes such form when designing exercise set.

Exemplary 2. (1) Please determine whether the following reactions can be carried out and provide the basis.

$$
\begin{gathered}
\mathrm{Zn}+\mathrm{Fe}^{2+}=\mathrm{Zn}^{2+}+\mathrm{Fe} \\
\mathrm{Fe}+\mathrm{Cu}^{2+}=\mathrm{Fe}^{2+}+\mathrm{Cu} \\
\mathrm{Cu}+2 \mathrm{Ag}^{+}=\mathrm{Cu}^{2+}+2 \mathrm{Ag} \\
\mathrm{Cu}+2 \mathrm{H}^{+}=\mathrm{Cu}^{2+}+\mathrm{H}^{2} \uparrow
\end{gathered}
$$

(2) From reaction: $\mathrm{Zn}+\mathrm{Fe}^{2+}=\mathrm{Zn}^{2+}+\mathrm{Fe}$, reducibility: $>$. Please determine: The severity of reaction when $\mathrm{Zn}$ and $\mathrm{Fe}$ react with hydrochloric acid of the same concentration respectively: $>$. Thus, what is the relationship between metal activity and reducibility of metal elements?

(3) Given: $\mathrm{Hg}+2 \mathrm{Ag}^{+}=\mathrm{Hg}^{2+}+2 \mathrm{Ag}, \mathrm{M}+\mathrm{Hg}^{2+}=\mathrm{M}^{2+}+\mathrm{Hg}$, please determine for the following reaction: $\mathrm{M}+2 \mathrm{Ag}^{+}=\mathrm{M}^{2+}+2 \mathrm{Ag}$;

1) Whether the reaction $\mathrm{M}+2 \mathrm{Ag}^{+}=\mathrm{M}^{2+}+2 \mathrm{Ag}$ can occur? What is the basis?

2) Given that neither mercury nor silver can replace the hydrogen in the acid, whether metal $M$ to replace the hydrogen in the acid? Please analyze and elaborate.

(4) Sodium is known to be a metal. Please determine according to the order of metal activity:

1) What is the reducibility of sodium metal? How active is the metal?

2) Aluminum can be ignited in oxygen, and Magnesium can be ignited in the air. Please judge the reaction conditions of sodium and oxygen and write out the chemical equation.

3) Can metal sodium displace hydrogen from acid?

4) Magnesium can produce displacement reaction with hot water. Can sodium replace hydrogen in the water? If yes, please determine the severity of the reaction, and write the chemical equation of the reaction [11].

Students design by themselves and carry out relevant verification experiments on the basis of inquiry. It not only allows students to complete the learning process, but also realized the attempt and simulation of scientific discovery and research [12]. What's more, by the combination to redox reaction, it achieves the structural design of teaching content so as to inspire students' interests on learning chemistry and promotes the transforming of students' learning style to cultivate students' spirit of innovation and practical ability [5].

It can be seen from this question, this question takes specific examples of redox reaction as materials, through comparative analysis; the basic principle is extracted and applied to the learning of new substances (sodium metal) and new knowledge. The learning process of metal sodium is the process of logical thinking, application of redox reaction principle, continuous innovation and enrichment of elemental compound knowledge under the application of redox reaction principle, and reasoning, discovery and experimental verification. Such learning method truly realized students' independent Inquiry-based and discovery-based learning, reflects the spirit of pursuit andability of thinking, which has changed the way students learn, so the quality of learning has undergone a qualitative change.

This set of one assignment per lesson was first presented in the open teaching seminar of high school chemistry teaching in Zibo. Teachers responded that there is no boundary and no limit to teaching ideas, and you can almost do anything as long as you have an idea. A week after the meeting, schools feedback that classroom-teaching effect is excellent, particularly, those with fairly good enrollment. Students prefer this kind of method, which greatly stimulates students' intrinsic challenge, activated students' creativity, and students' 
passion for Chemistry has surged unprecedentedly.

\subsection{Problem Summary Solution Type}

The so-called problem summary solution type one assignment per lesson is to concentrate students' problems in their homework, and the teachers compile an exercise by summarizing and apply it to one assignment per lesson (one assignment per lesson is printed on the worksheet, but the teachers do not require students to it before the class). Students have done similar exercises in their homework, they complete the one assignment per lesson based their understanding on the relevant knowledge. According to the homework problem record, the teachers ask the students who make typical mistakes to answer one assignment per lesson in the lesson. In this way, the most typical problems can be exposed, and through teachers' questioning, the ideological roots of students' problems can be excavated, the problems can be solved fundamentally.

For example, many students can write electrode reaction equation. However, when both the cathode and the anode appear at the same time, they usually neglect the principle that the number of electron transfer between two poles must be equal and writing requirements. It is manifested as failure to use minimum common multiple on the cathode and anodeto represent the conservation of gain and loss electrons, and they often make mistakes in homework. Consequently, the following exercises can be designed to allow students to find problems and clarify the principles and writing requirements.

Exemplary 3 . Write the following equations and analyze the answers.

(1) Write the electrode equation of the cathode in the electrolytic alumina reaction:

(2) Write the chemical equation of the total reaction of electrolytic alumina:

Rewrite the total reaction equation into the electrode equation of anode and cathode:

Cathode: Anode:

(3) Comparing the electrode equation of the above two cathodes, any difference? What is the principle?

For knowledge systems that are highly theoretical, abstract and deep understanding needs, students tend to have a series of problems in understanding and application. From origin to influencing factors and application etc., teachers canorganize a series of questions into progressive small questions or problem sets in a knowledge context, or multiple options in the multiple choice questions. Through students' analysis of each option, and teachers' close questions for the preset questions, to achieve the construction of a comprehensive and systematic knowledge and analysis system, and discover, expose and solve students' problems in the process of construction.

For example, when students are learning about chemical equilibrium, they lack understanding on the chemical equilibrium and its movement, especially when the principle is reflected in the image, students' "ability to accept, absorb and integrate chemical information" is weak. Thus, the most familiar reaction example and most common image form are used when compiling picture questions about chemical equilibrium. It allows students to learn with the adequate time and autonomous learning style, propose questions based on learning, and stimulate students' intellectual curiosity and thinking to a maximum extent, in order to form communication between principles and images, facts and analytical interpretation, enhance students' understanding of basic principles and various forms of application, as well as their ability to analyze and solve problems with the information obtained.

Example 4. (1) Figure 3 shows the relationship between reaction rate, reaction process and reaction time in a certain period of time when $\Delta \mathrm{H}<0$ for reaction $\mathrm{N}_{2}(\mathrm{~g})+3 \mathrm{H}_{2}(\mathrm{~g}) \leftrightharpoons$ $2 \mathrm{NH}_{3}(\mathrm{~g})$. The following statement is correct ( )

A. Only $t_{0}-t_{1}$ and $t_{5}-t_{6}$ are the time intervals for the reaction to reach equilibrium in the figure.

B. he change of the external condition at $t_{4}$ is that N2 concentration increases

C. The change of the external condition at $t_{3}$ is an increase in temperature

D. The equilibrium constants of the reaction remain unchanged after changing the condition at $t_{3}$

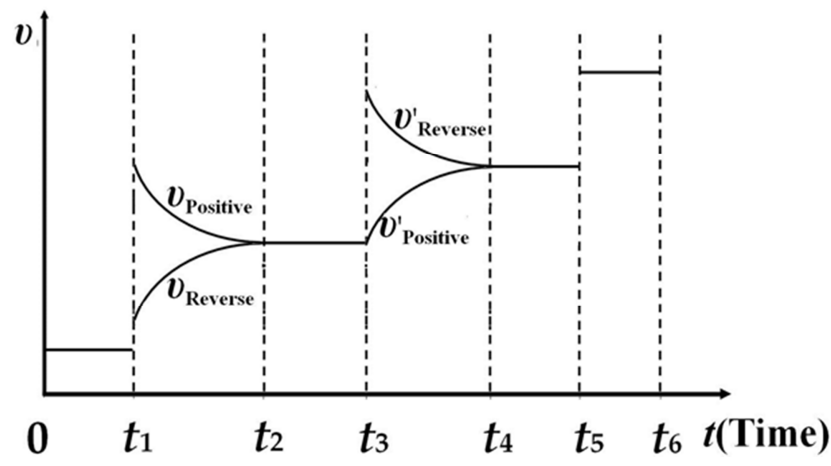

Figure 3. Relationship between reaction rate and reaction time of ammonia under certain conditions (1).

After the students complete their exercises, teachers start to ask questions. This enables students' understanding of knowledge from concrete to abstract, and example to principle. The questions are as follows:

(2) Please answer the following questions for the $v-t$ figure in the previous question:

1) Please write down the time period in which the chemical equilibrium is reached.

2) Please write down the time period in which the chemical equilibrium shifts.

3) Please analyze the reasons for the changes in $t_{1}-t_{2}$.

4) Comparing the two major differences between the curves of $t_{1}-t_{2}$ and $t_{1}-t_{2}$, and analyze its principle.

5) Please analyze the cause of $t_{5}-t_{6}$ curve.

According to the students' answers, teachers can ask well-timed questions step by step, such as:

1) What is the essence of chemical equilibrium? What "invariant quantities" or "equivalent quantities" are produced due to this essential cause?

2) What is the root cause of the destruction of chemical 
equilibrium? What is the shift of chemical equilibrium? What is the relationship between the direction of chemical equilibrium shift and the change of positive and negative chemical reaction rates? What is the final result in terms of the reaction rate?

3) What are the factors affecting chemical equilibrium? How do they affect chemical equilibrium and have chemical equilibrium shift? What is the direction of shift? How does it show up in the figure?

4) What should be noticed when analyzing $v$-t figure? What is the basic sequence of reviewing the figure?

5) What are the main forms of image change in v-t figure? Please analyze and elaborate from the perspective of its principle.

Finally, the teachers change the questions, and students finish the following question independently, to consolidate students' understanding results and test teachers' teaching effect.

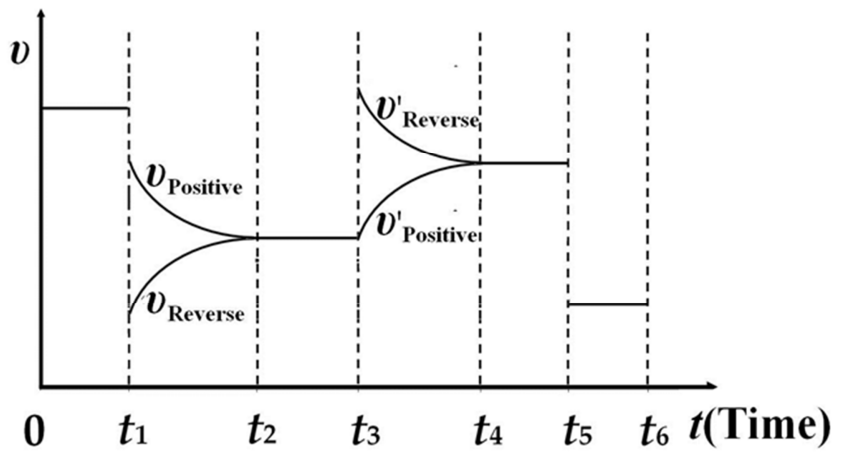

Figure 4. Relationship between reaction rate and reaction time of ammonia under certain conditions (2).

(3) Figure 4 shows the relationship between reaction rate, reaction process and reaction time in a certain period of time when $\Delta \mathrm{H}<0$ for reaction $\mathrm{N}_{2}(\mathrm{~g})+3 \mathrm{H}_{2}(\mathrm{~g}) \leftrightharpoons 2 \mathrm{NH}_{3}(\mathrm{~g})$. Please answer the following questions based on Figure 4:

1) How many chemical equilibrium states are there in this figure?

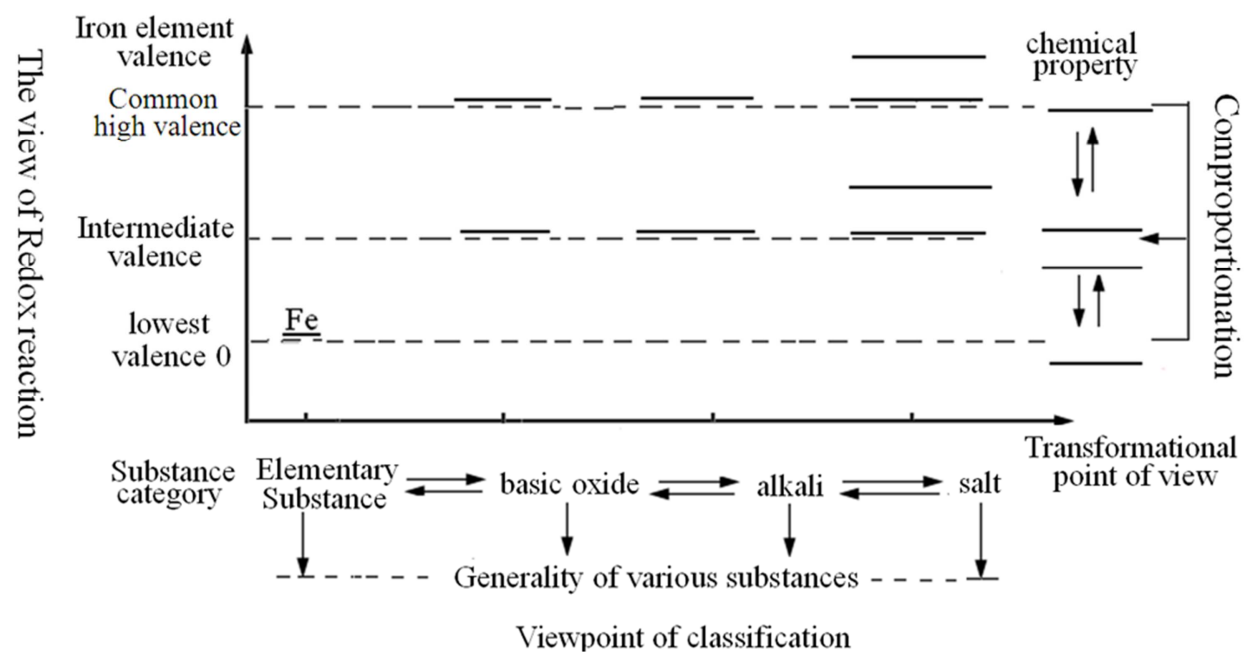

Figure 5. Two-Dimensional Map of Recognition of Iron Elements and Their Compounds.

Question 1. Please talk of your understanding on this chart. Question 2. Please fill the chemical formula of iron and its
2) How many chemical equilibrium shifts are there in this figure?

3) Try to analyze what are the factors for the change at $t_{1}$ ?

4) Try to analyze what are the factors for the change at $t_{3}$ ?

5) Try to analyze what are the cause for the change at $t_{5}$ ?

\section{The Development and Improvement of One Assignment Per Lesson}

The teaching of teaching and learning is for learning, while the learning is not for knowledge but to form scientific opinions and methods of thinking and improve the thinking ability and cultivate scientific competence during the process of learning knowledge. Therefore, the design of One Assignment per Lesson must be in accordance with students' actual situation, teaching content and requirements. And it must seize the opportunity to create materials for students taking solid foundation to develop innovation, materials for students training scientific opinions and materials for students cultivating core competence, making students realize scientific thought and form viewpoints and methods of knowing science and found a foundation for forming scientific learning strategy [13].

For example, while learning iron of metal in Chemistry I, students who learnt the sodium and aluminium have learnt the thinking method of classification and principles of redox reaction and so on [10]. So, for the teaching design, teachers should construct the methods and principles of scientific thought into the strategy model of the learning elements and their compounds of knowledge and create "Model Cognition" for enriching learning contents and carry out modeling teaching, while they should apply and guide the learning of elements (eg. Iron) and their compounds for a deep learning [14].

Example 5. Please read the following chart and answer questions below:

common compounds into the horizontal line, and deduce the chemical property of iron as well as write down its chemical 
reaction equation (or ionic equation)

Question 3. Please summary the chemical property of iron, and explain your viewpoints of analysis.

Question 4. Please design experiment to verify your understanding on the chemical property of iron.

Question 5. According to your understanding on the above learning process, please summary the basic ideas and methods of viewpoints on learning elements and their compounds.

It shows that, the knowledge of iron and its compounds in this course is not main learning target. The pursuit of teaching design is to encourage students to study independently, increase confidence, develop thinking, experience scientific attitude and science spirit, summary learning meanings, extract learning strategy and form science competence. Such teaching design promotes directly students' personalized development in an initiative, lively, scientific and comprehensive way, and cultivates students' scientific literacy and the ability of lifelong learning, founding a foundation for students' lifelong development [5]. This is the goal of One Assignment per Lesson pursuing.

\section{Conclusion: The Multi Values of One Assignment Per Lesson}

In conclusion, One Assignment per Lessonfeatures multi-functions.

In terms of basic knowledge, it can expose and solve students' problems, and help teachers to analyze problems from multiple points of view with the multi-forms and to integrate knowledge, explaining, understanding, thinking and application, providing students with a platform to understand basic knowledge further and find their own problems of deeper levels.

In terms of the way to study, it achieves that students can creatively study and apply, and trains students' ability to extract and apply new information, logical thinking ability and knowledge understanding and application ability, learning from wrong examples, as well as developing science teaching and learning from comprehension; it guides students to learn not by feelings but by scientific thinking, methods and model cognition.

In terms of students' development, this is the goal of One Assignment per Lesson pursuing. In the wrong example teaching, students are willing to express their opinions and expose their problems, and ready to exchange views with classmates and teachers [15]. Students can truly form a learning style based on independent thinking, communication and cooperation, and equipped with scientific quality of learning scientific knowledge with scientific attitude and ideological method, truly and genuinely form the great practical attitude, brave pursuit of their thoughts and perfect scientific attitude, and form right values, necessary quality and key ability. Therefore, the goal of one assignment per lesson is to teach knowledge and cultivate people.

\section{References}

[1] Xiaopeng Huai, Jinyu Hou and Xuehai Li. "The Research and Rractice on the Activity of 'One Assignment per Day' of Science of Secondary School" [J]. Secondary School Teaching Reference, 2016, (17): 105-106.

[2] Shangyi Ren. "The Function of 'One Assignment per Day' on Improving Students' Ability of Independent Learning Examination"'[J]. Weekly, 2014, (86): 174.

[3] Ruibin Chen. "The Practice and Application of the Teaching Model of Chemistry PIC" [J]. Chemistry Teaching and Learning, 2016, (05): 48-51.

[4] Jun Dong. "Inspire Students' Mind by Problems" [J]. Educational Exploration, 2016, (7): 49-54.

[5] Ministry of Education of the People's Republic of China. Standards of High School Chemistry Curriculum (2017 version) (S). Beijing: People's Education Press, 2018.

[6] Wenbin Yang. "Status Survey on Interactive Teaching and Problems and Solutions of High School Chemistry Curriculum" [J]. Chemistry Education, 2016, 37 (13): 42-47.

[7] Tianshan Sun. "Pre-preparing for Chemistry Assignment with the New Lessons" [J]. Chemistry Education, 2012, 33 (11): 25-27.

[8] Comprehensive Ability Test of Science in National Unified Examination for Admission of General Colleges and Universities in 2008 (II), 26.

[9] Jun Dong. "Apply Scientifically the Modeling Teaching" [J]. Modern Education, 2015, (11): 45-46.

[10] Xinqi Song. "Standard Chemistry Experiment Textbook of High School Chemistry Curriculum": Chemistry I . Beijing: People's Education Press, 2007: 46.

[11] Jun Dong. "Know Elemental Chemistry with Viewpoints and System of Unity of Opposites" [J]. Secondary School Teaching Reference, 2016, (9): 6-9.

[12] Caixia He. "Progressive Teaching of 'Promoting to Solve Students' Problems and Form Their Own Ideas" [J]. Chemistry Education, 2018, (10): 51-56.

[13] Zhixin Liu. "Several Problems Deserving a Further Study on Implementing Science Courses" [J]. Chemistry Education, 2014, 35(15): 1-5.

[14] Chunyang Wang. "Case Study on Teaching Plan of Chemistry Classes for a Deep Learning" [J]. Chemistry Education, 2017, 38 (09): 34-37.

[15] Jibing Guo. "Taking Cases to Talk of the Practice and Ideas of Preparing Chemistry Assignments under the Background of New Courses". Teaching and Learning of Chemistry, 2011, (06): 55-56. 